\title{
Letter to the Editor: Limitations to Remote Electives in Pathology-a Medical Student's Perspective
}

\author{
Shaun $\operatorname{Rees}^{1}$ (D) $\cdot$ Robert Nelson-Sice $^{1}$ \\ Accepted: 19 November 2021 / Published online: 1 December 2021 \\ (c) The Author(s) under exclusive licence to International Association of Medical Science Educators 2021
}

\section{Dear Editor,}

We greatly enjoyed reading a recent paper regarding the implementation of remote teaching in international histopathology electives [1] and had a few reflections as final year medical students with a particular interest in histopathology.

Firstly, to see the institution reviewing their practices in order to provide favourable outcomes for their students is commendable. Whilst we agree with the positives mentioned, increased globalisation of teaching and increased flexibility and individualisation of learning, the limitations for this format of remote elective in pathology were not explored thoroughly.

As medical students, we view our final year elective as an opportunity to explore the career that has most interested us in our studies, and we feel this format of elective detracts from the actual daily activities and challenges experienced by a histopathologist. Firstly, the lack of access to observation/completion of dissection was not mentioned in this review — as students on a case/problem_based learning course, the opportunity to watch and partake in dissection facilitates learning of surgical procedures, rationalising dissection in anatomical space, and helps in developing diagnosis via macroscopic description. Additionally, whilst some specialised biomedical scientists are completing specimen dissection in the UK, more complex cases are ultimately viewed by pathologists and thus students interested in the specialty will be missing out on a large aspect of the career in this format of teaching.

Additionally, whilst essential during these times, remote electives have further drawbacks not mentioned in this review unlike one completed by an alternative institution [2]. Where they saw limitations in the student's ability to engage emotionally, cognitively, and physically with the course - we felt the survey design in this study could have allowed students to reflect and discuss more around issues experienced as opposed to a simple Likert format.

In summary, whilst it is refreshing to see the teaching of diagnostic microscopy progressing and modernising - we fear this paper did not address the limitations and missed learning opportunities that this elective format is susceptible to.

\section{Declarations}

Ethical Approval NA.

Informed Consent NA.

Conflict of Interest The authors declare no competing interests.

\section{References}

1. Guiter G, Sapia S, Wright A, Hutchins G, Arayssi T. Development of a remote online collaborative medical school pathology curriculum with clinical correlations, across several international sites, through the Covid-19 pandemic. Med Sci Educ. 2021;31(2):549-56.

2. Tanaka K, Ramachandran R. Perceptions of a remote learning pathology elective for advanced clinical medical students. Acad Pathol. 2021;8:237428952110068.

Publisher's Note Springer Nature remains neutral with regard to jurisdictional claims in published maps and institutional affiliations.

Shaun Rees

m1801905@sgul.ac.uk

1 St Georges University London, Cranmer Terrace,

Tooting, London SW17 0RE, UK 